\title{
Fundamental characteristics of material removal and surface formation in diamond turning of porous carbon
}

\author{
Mehdi Heidari and Jiwang Yan* \\ Department of Mechanical Engineering, \\ Keio University, \\ Hiyoshi 3-14-1, Kohoku-ku, \\ Yokohama 223-8522, Japan \\ Email: heidarimehdi@keio.jp \\ Email: yan@mech.keio.ac.jp \\ *Corresponding author
}

\begin{abstract}
Porous carbon is an important material for manufacturing ultraprecision air bearings. This paper investigates the material removal mechanism and surface quality of porous carbon in diamond turning process. A total of 32 diamond turning tests were performed and the effects of feed rate, depth of cut, cutting speed, and tool rake angle were investigated. Scanning electron microscopy of the machined surface showed that three types of material removal mechanisms occurred in the diamond turning process, which was influenced by experimental conditions. Analysis of variance of experimental data demonstrated that feed rate had the most dominant effect on surface roughness, followed by depth of cut, whereas cutting speed has little effect. Tool rake angle effects material removal behaviour in a different way from that of diamond turning of other brittle materials, showing that a negative rake angle is disadvantageous. The results also indicated that by controlling the machining conditions, surface roughness, core roughness and the bearing area curve of the machined surface were controllable, and there was a $25 \%$ decrease in the percentage of porosity after machining. It was demonstrated that diamond turning can be used as an efficient method to fabricate high-precision surfaces on porous carbon for air bearing applications.
\end{abstract}

Keywords: porous carbon; diamond turning; surface roughness; porosity; bearing area curve; material removal mechanism.

Reference to this paper should be made as follows: Heidari, M. and Yan, J. (2017) 'Fundamental characteristics of material removal and surface formation in diamond turning of porous carbon', Int. J. Additive and Subtractive Materials Manufacturing, Vol. 1, No. 1, pp.23-41.

Biographical notes: Mehdi Heidari graduated from Ferdowsi University of Mashhad, Iran with a Master's degree in 2009 and a Bachelor's degree from Iran University of Science and Technology in 2003, both in Mechanical Engineering. He is a $\mathrm{PhD}$ student at Keio University under supervision of Professor Jiwang Yan since 2014. He is engaged in micro/nano and ultraprecision cutting processes research and development.

Jiwang Yan is a Professor in the Department of Mechanical Engineering, Graduate School of Science and Technology, Keio University. His research interests include ultraprecision machining, micro/nano mechanics, laser processing of functional materials, micro/nano forming and glass press moulding technologies. 
This paper is a revised and expanded version of a paper entitled 'Investigation on surface formation mechanism of porous carbon in diamond turning' presented at The 8th International Conference on Leading Edge Manufacturing in 21st Century (LEM21 2015), Kyoto, Japan, 18-22 October 2015.

\section{Introduction}

An air bearing is a new generation of bearing having advantages such as zero friction and wear, no need to be lubricated, high precision and high speed. Air bearings are increasingly used in various fields such as ultra-precision machine tools. One of the most important parts of air bearing is porous media, where porous carbon has been one of the best materials for this purpose. Owing to the special surface structure of porous carbon, if there is an air supply failure, the counterpart surface will not be damaged and bearing may run without air pressure. Moreover, compared with non-porous materials, porous carbon provides a uniform distribution of air pressure, which enhances the spindle rotation accuracy. However, the surface quality of porous carbon depends on its machining method. To improve the service life, load capacity and wear resistance of bearing parts, it is essential to reduce surface peak height and increase core roughness depth during the machining process. Nevertheless, there are a few problems such as surface fractures, sharp protrusions and grain dislodgements, etc., in conventional grinding and cutting of porous carbon, which limits the surface quality improvement.

A few researches have been carried out on the fabrication of bulk porous carbon (Fan et al., 2015; Wei and Wang, 2015) to produce porous structure in the base material. However, to date, there is no available literature on the mechanism of cutting porous carbon, although there are a few reports of machining of other porous materials. For example, Chen et al. (2004) argued the effects of tool geometry, tool material properties and main machining parameters on porosity of porous tungsten for application as dispenser cathodes. Nee et al. (2013) applied infiltrate-free method for machining porous tungsten and they tried to control brittle micro-fracture to obtain the suitable surface porosity. Pusavec (2012) used multi-objective optimisation model based on genetic algorithms to achieve the best machining performance in cutting porous structure under cryogenic condition by predicting the optimal cutting input parameters.

In this study, we try diamond turning of porous carbon to evaluate the effects of cutting parameters on the mechanisms of material removal and surface formation. Three machining variables were selected in order to design the matrix of experiments based on the Taguchi approach. Then, by keeping these three variables constant, the effect of tool rake angle on material removal mechanism was investigated. Statistical method of analysis of variance (ANOVA) had been used to consider the effect of these parameters. The results indicated the possibility of direct rapid fabrication of precision air bearing surfaces of porous carbon by using diamond turning.

\section{Design of experiments}

In order to investigate the mechanism for diamond turning of porous carbon experimentally, the face turning method was applied by using an ultra-precision lathe. Figure 1 schematically shows the model for diamond turning of porous carbon. 
Figure 1 Schematic model for diamond turning of a porous material (see online version for colours)

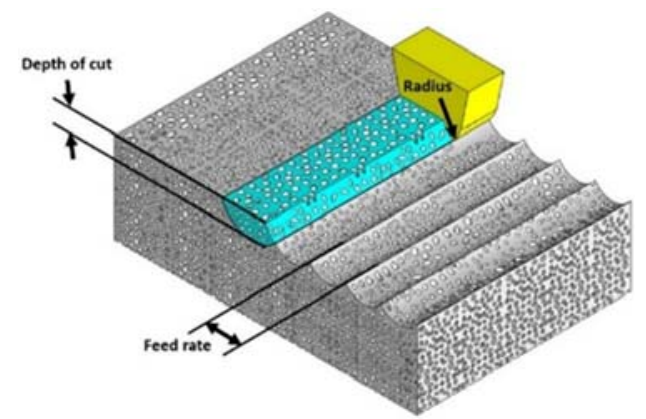

Three independent variables including feed rate, cutting speed and depth of cut, each in four levels were considered in these experiments. As Table 1 shows, the range of cutting parameters used were: feed rate $(f)=25,50,75,100 \mathrm{~mm} / \mathrm{min}$, cutting speed $(v)=30,60,90,120 \mathrm{~m} / \mathrm{min}$ and depth of $\operatorname{cut}(a)=0.2,0.4,0.6,0.8 \mathrm{~mm}$.

Table 1 Independent variables and their levels

\begin{tabular}{llcccccc}
\hline No. & Factors & Units & Notation & Level -2 & Level -1 & Level +1 & Level +2 \\
\hline 1 & Feed rate & $\mathrm{mm} / \mathrm{min}$ & $f$ & 25 & 50 & 75 & 100 \\
2 & Cutting speed & $\mathrm{m} / \mathrm{min}$ & $v$ & 30 & 60 & 90 & 120 \\
3 & Depth of cut & $\mathrm{mm}$ & $a$ & 0.2 & 0.4 & 0.6 & 0.8 \\
\hline
\end{tabular}

Table 2 Design of experiment matrix

\begin{tabular}{lccc}
\hline No. & Depth of cut $(\mathrm{mm})$ & Feed rate $(\mathrm{mm} / \mathrm{min})$ & Cutting speed $(\mathrm{m} / \mathrm{min})$ \\
\hline 1 & 0.2 & 25 & 30 \\
2 & 0.2 & 50 & 60 \\
3 & 0.2 & 75 & 90 \\
4 & 0.2 & 100 & 120 \\
5 & 0.4 & 25 & 60 \\
6 & 0.4 & 50 & 30 \\
7 & 0.4 & 75 & 120 \\
8 & 0.4 & 100 & 90 \\
9 & 0.6 & 25 & 90 \\
10 & 0.6 & 50 & 120 \\
11 & 0.6 & 75 & 30 \\
12 & 0.6 & 100 & 60 \\
13 & 0.8 & 25 & 120 \\
14 & 0.8 & 50 & 90 \\
15 & 0.8 & 75 & 60 \\
16 & 0.8 & 100 & 30 \\
\hline
\end{tabular}


A full factorial set of experiments would require 64 experimental test (three factors at four levels). In this work, Taguchi design of experiments (DOE) was used to reduce the number of tests to 16 , which is called $\mathrm{L}_{16}$ Taguchi DOE. This design is listed in Table 2 . This $\mathrm{L}_{16}$ Taguchi set of experiments, along with 16 other tests were used to clarify effect of different parameters on material removal mechanism and surface quality.

\section{Experimental setup}

The cutting experiments were conducted on a three-axis CNC ultraprecision machine, NACHI ASP-15 (NACHI-FUJIKOSHI CORP.). The porous carbon workpiece $(30.0 \mathrm{~mm} \times 20.0 \mathrm{~mm} \times 10.0 \mathrm{~mm})$ with purity of 0.99 , porosity of $35 \%$ and average pore size of $4 \mu \mathrm{m}$, supplied by TANKEN SEAL SEIKO CO., LTD. was used in the experiments. In order to fix the workpiece to the spindle and adjust the cutting speed, a workpiece holder was designed and fabricated. This holder uses a sliding mechanism to change cutting speed by adjusting the distance between the workpiece and the centre of spindle, and then the workpiece was fixed using two screws. In addition, on the opposite side of the workpiece, a metal piece was fixed to keep dynamic balance during spindle rotation, as illustrated in Figure 2.

Figure 2 Photograph of experimental setup (see online version for colours)

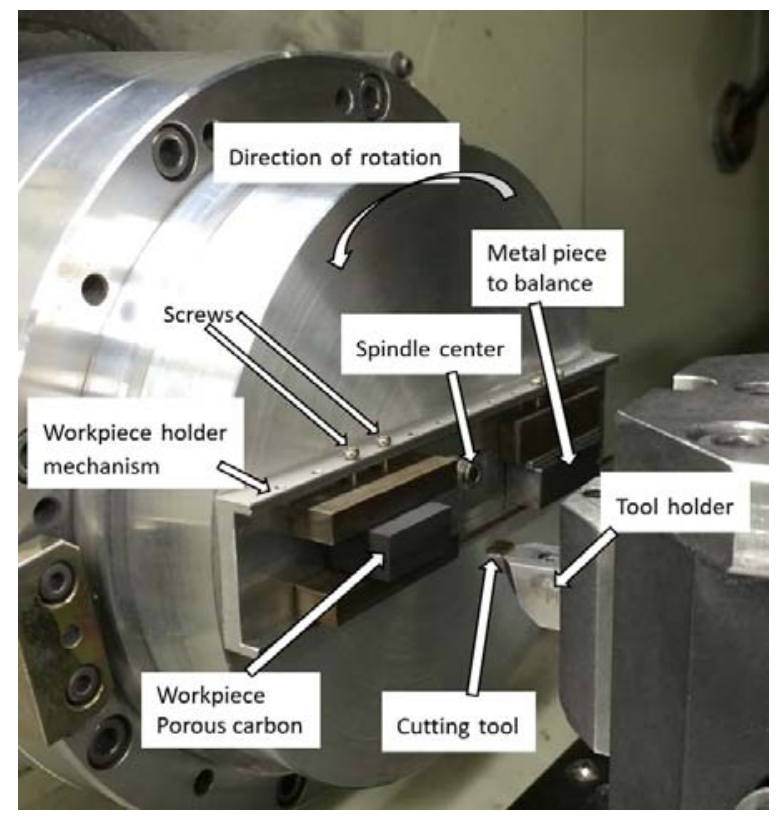

A commercially available diamond cutting tool with a nose radius of $10 \mathrm{~mm}$, rake and clearance angles of $0^{\circ}$ and $6^{\circ}$, respectively, was used in experiments. The tool geometry is shown in Figure 3(a). To survey the influences of tool rake angle on cutting mechanism, four experiments were performed under conditions shown in Table 3. For the purpose of changing rake angles, four tool holders having various slopes were designed 
to enable rake angle of $0^{\circ},-15^{\circ},-30^{\circ}$ and $-45^{\circ}$, as shown in Figure 3(b). Thus, in all the tests, the same diamond insert with $0^{\circ}$ rake angle was used. In this case, the relief angle was changed accordingly, the effect of which was neglected.

Figure 3 (a) Tool insert geometry (b) Tool holders for rake angle adjustment (see online version for colours)

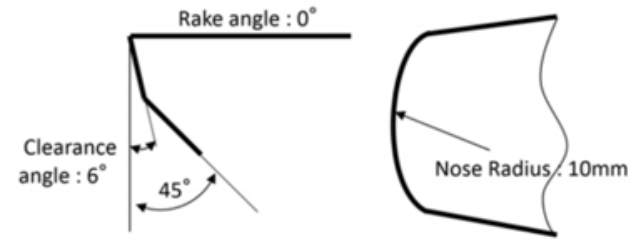

(a)

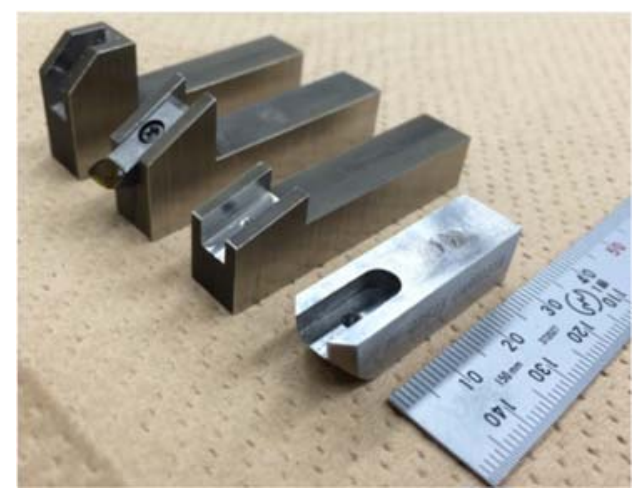

(b)

Table 3 Experimental conditions for tool rake angle effect

\begin{tabular}{lcccc}
\hline No. & Rake angle (degree) & Depth of cut $(\mathrm{mm})$ & Feed rate $(\mathrm{mm} / \mathrm{min})$ & Feed rate $(\mathrm{mm} / \mathrm{min})$ \\
\hline 1 & 0 & 0.4 & 50 & 60 \\
2 & -15 & 0.4 & 50 & 60 \\
3 & -30 & 0.4 & 50 & 60 \\
4 & -45 & 0.4 & 50 & 60 \\
\hline
\end{tabular}

In order to evaluate the surface roughness, a white light interferometer was used and the surface profile was analysed by the Talymap software (Taylor Hobson Ltd.). According to Taguchi $\mathrm{L}_{16}$ DOE matrix, 16 experiments were performed and after each experiment, eight different areas of the machined sample were measured and analysed and then the average was taken as the final result. In addition, scanning electron microscopy (SEM) and field-emission scanning electron microscopy (FE-SEM) were used to observe the sample surfaces. These images were then used for analysing the percentage of surface porosity using the ImageJ software. 


\section{Results and discussion}

\subsection{Categories of material removal behaviour}

To clarify the mechanism of material removal in cutting, the machined surfaces were observed by FE-SEM. Figure 4(a) and Figure 4(b) are two SEM photographs of sample surface, before and after cutting, respectively. Before machining, the surface is very rough, with protruding carbon particles and big craters. After machining, however, the surface has become obviously flatter, where some of the grains have been sliced to be very smooth.

Figure 4 SEM images of porous carbon surfaces, (a) before (b) after machining (X 500 magnification)

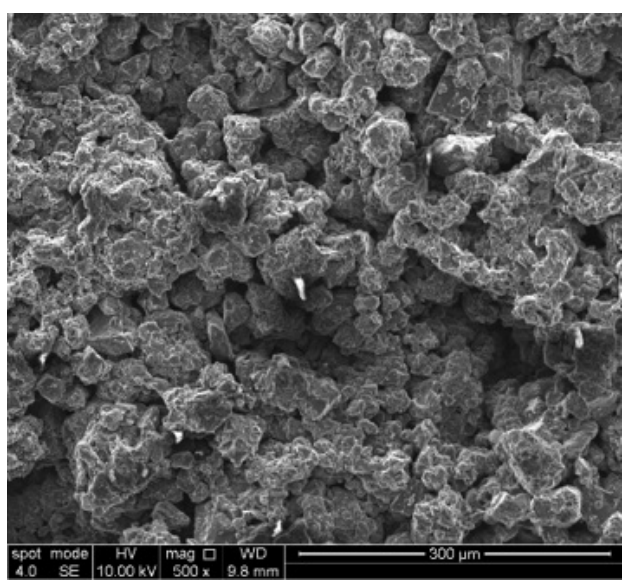

(a)

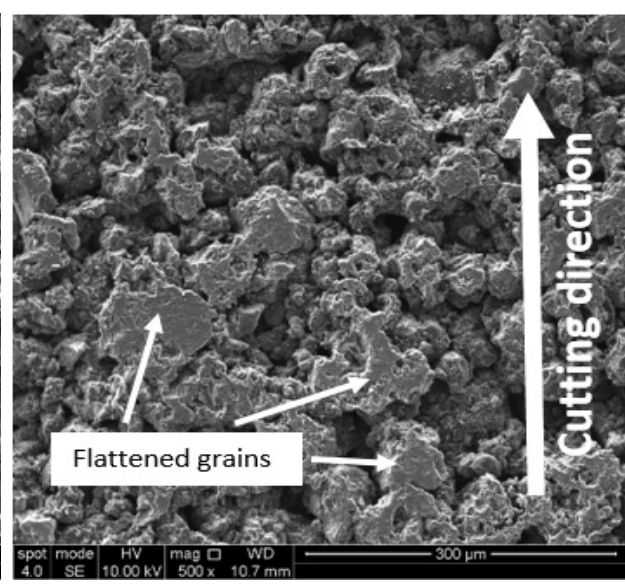

(b)

Through observation at higher magnifications, three types of material removal mechanisms were identified in the machining of porous carbon, namely, plastic deformation, brittle fracture, and grain rotation. Figure 5(a) shows the first type of material removal, i.e., plastic deformation. Due to the contact of tool and workpiece surface, big carbon grains have been sliced and partially removed by plastic deformation. This might be caused by the ploughing forces of the tool against the workpiece surface.

Figure 5(b) gives an example of the second mechanism, i.e., brittle fracture. In Figure 5(b), at the location indicated by 'a', the upper part of the grain aggregation was removed due to brittle fracture along the boundary with other grains, without appearance of plastic deformation. These phenomena took place when the bonding strength of interface between carbon particles is less than shear strength of the bulk of carbon grain, and brittle fracture is easy to occur along the grain boundaries by the micro impacts of the cutting tool. This kind of crack propagation mechanism in different directions leads to high surface roughness. Another type of brittle fracture occurs inside a single carbon grain bulk. As indicated by ' $b$ ' in Figure 5(b), a part of carbon grain is separated by crack generation from the grain bulk, leaving curved fracture edges in the craters (Totten et al., 2003). 
Figure 5 Three typical material removal mechanisms, (a) plastic deformation (b) brittle fracture (c) grain rotation

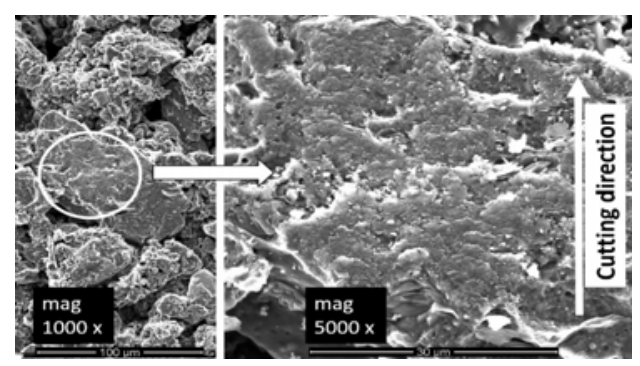

(a)

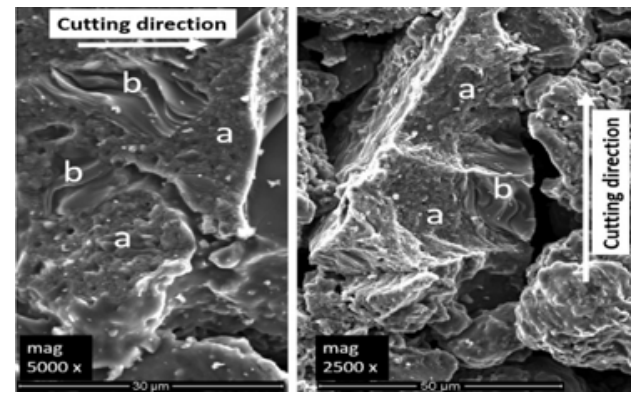

(b)

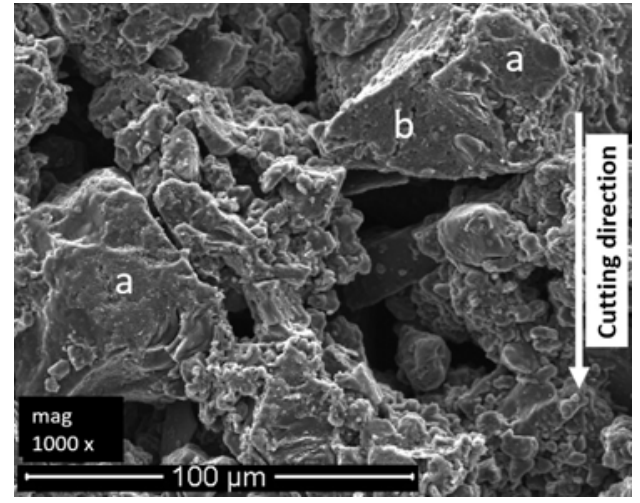

(c)

The third phenomenon observed is grain rotation. As shown in Figure 5(c), three flat surface areas indicated by ' $a$ ' and ' $b$ ' are seen, which are likely to be cut through plastic deformation. Apparently, the flat ' $b$ ' is not in the same plane as the other two flat ' $a$ '. This indicates that some of carbon particles had been rotated due to the cutting force from the tool. The cutting force exceeded the bonding strength of the grains, leading to grain rotation along the grain boundaries during cutting. The schematic illustration of machining process involving these three mechanisms of material removal is shown in Figure 6. 
Figure 6 Schematic illustration of cutting mechanisms for porous carbon involving, (a) plastic deformation (b) brittle fracture (c) grain rotation (see online version for colours)

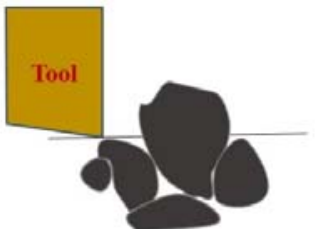

Plastic Wave deformation mechanism

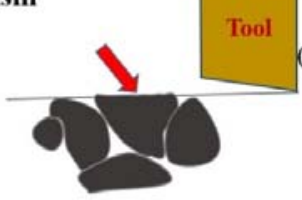

(a)

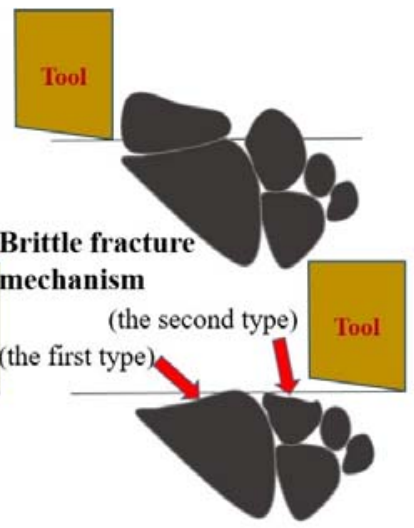

(b)

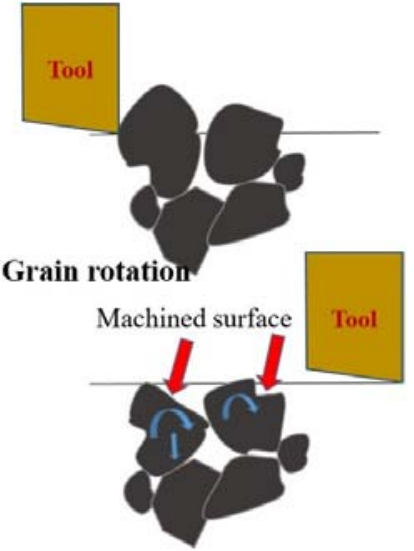

(c)

Figure 7 Observation results of chips, (a) and (b) show chips entering pores during cutting process (c) and (d) show increase of chip size with depth of cut (see online version for colours)

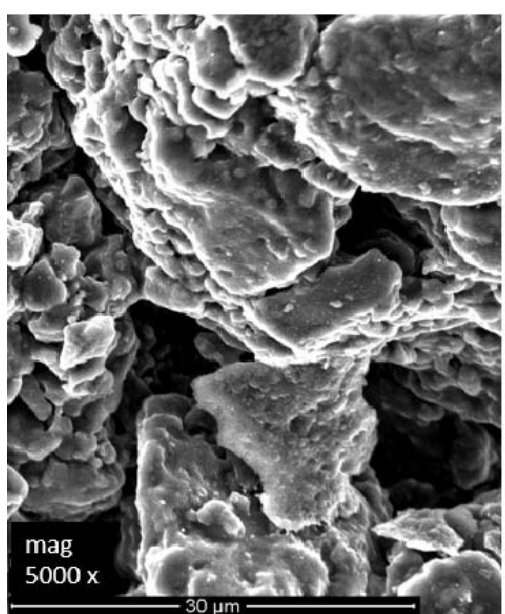

(a)

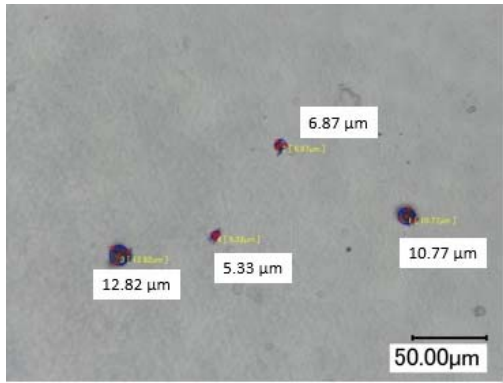

(c)

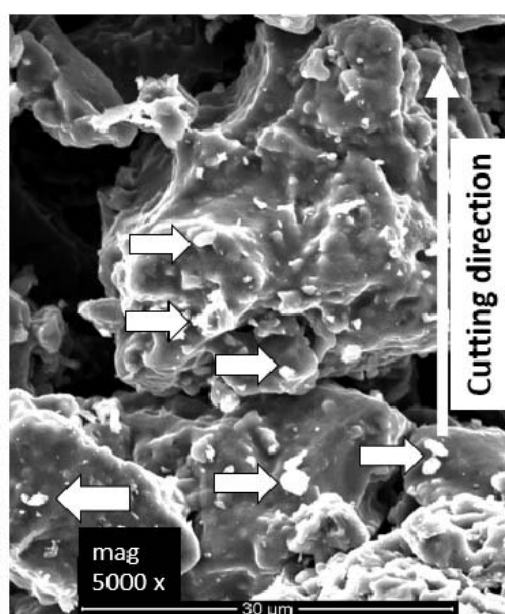

(b)

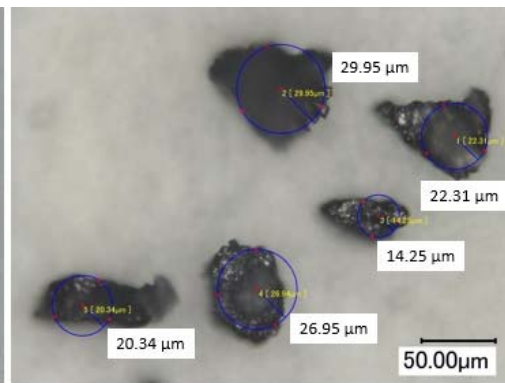

(d) 
In addition to the above mentioned material removal mechanisms, we found that a few particles had been pressed into the pores of the workpiece without any deformation or fracture, as shown in Figure 7(a) and Figure 7(b). After collecting the chips and observing the chips by SEM, we found that the chip size increase with depth of cut. As shown in Figure 7(c), the average radius of chips in machining condition of $0.2 \mathrm{~mm}$ depth of cut is less than $10 \mu \mathrm{m}$, this average size increased to 20 to $30 \mu \mathrm{m}$ as depth of cut reaches to $0.8 \mathrm{~mm}$ in Figure $7(\mathrm{~d})$.

\subsection{Effects of machining parameters on cutting mechanisms}

Next, the correlation between machining parameters and material removal mechanism was investigated. In order to study the impacts of feed rate and depth of cut, four individual experimental tests were carried out at the same the cutting speed $60 \mathrm{~m} / \mathrm{min}$ as shown in Table 4.

Table 4 Experimental conditions for individual effect of depth of cut and feed rate

\begin{tabular}{lcc}
\hline No. & Depth of cut $(\mathrm{mm})$ & Feed rate $(\mathrm{mm} / \mathrm{min})$ \\
\hline 1 & 0.2 & 25 \\
2 & 0.2 & 100 \\
3 & 0.8 & 25 \\
4 & 0.8 & 100 \\
\hline
\end{tabular}

Figure 8 The effect of depth of cut and feed rate on cutting mechanisms, (a) plastic deformation (b) wavy plastic deformation and brittle fracture, type a (c) wavy plastic deformation and brittle crack, type $b(d)$ brittle fracture, type a
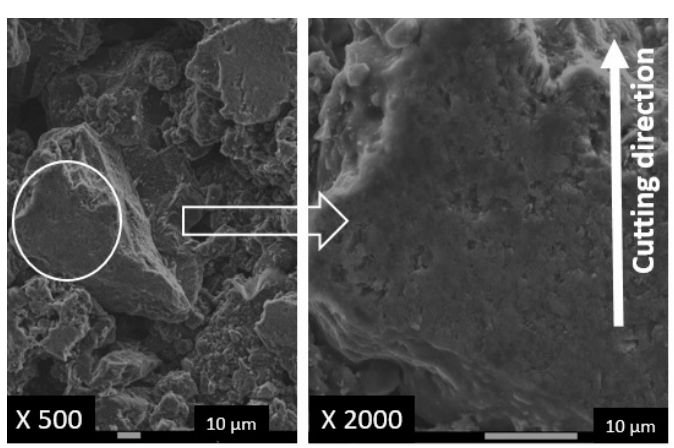

(a)

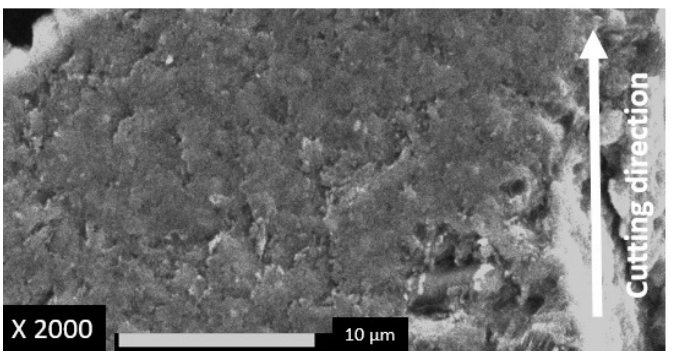

(c)

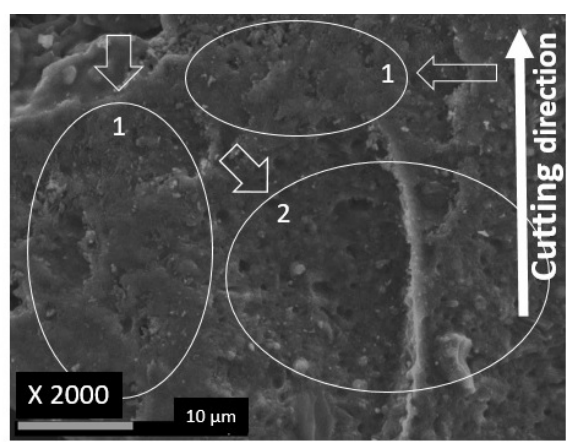

(b)
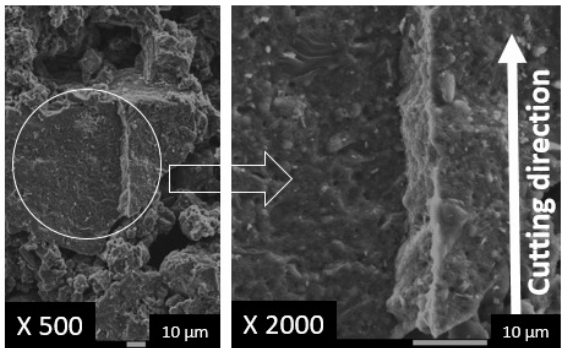

(d) 
FE-SEM observation of the machined surface indicated that in test 1 , the majority of cut surface was formed by the first mechanism, i.e., plastic deformation, as shown in Figure 8(a). In test 2, as shown in Figure 8(b), both plastic deformation, location indicated by ' 1 ', and brittle fracture (type a), location indicated by ' 2 ', were observed. Plastic deformation in this test was more significant with generation of surface waviness. In test 3, plastic deformation was more significant and the waviness is smaller compared with test 2, as shown in Figure 8(c). In addition, brittle fracture type b was also observed in some part of surface. As shown in Figure 8(d), brittle fracture (type a) or crack propagation was the dominating mechanism in test 4.

The aforementioned results indicates that increasing feed rate causes material removal mechanism to change from plastic deformation to brittle fracture. At high feed rates, crack propagation becomes the dominating mechanism (Mohammadi et al., 2015; Reddy, 2011). The effect of depth of cut was similar to that of feed rate, nevertheless, the effect level was less than that of feed rate.

\subsection{Effects of tool rake angle on cutting mechanisms}

As known from previous researches on the diamond turning of typical hard brittle materials such as single crystalline silicon, tool rake angle significantly influences the material removal mechanism (Yan et al., 2002). It has been well accepted that a negative rake angle is advantageous because it induces high compressive stress which prevent from brittle fracture. On the other hand, in metal cutting, as rake angle decreases, the shear angle decreases and hence shear energy dissipation and cutting forces increase (Kalpakjian and Schmid, 2009). However, to date, there have been no reports on effect of tool angle on cutting mechanisms of porous materials.

To investigate the effect rake angle on porous carbon cutting, experiments were performed under conditions shown in Table 3. Figure 9(a) is an FE-SEM image of the machined surface of test $1\left(0^{\circ}\right.$ rake angle), where plastic deformation is dominant. This kind of surface appearance was similar to those observed in test number 5 and 6 under conditions shown in Table 2. The machined surface obtained using the tool with $-15^{\circ}$ rake angle in test 2 also presented the plastic deformation mechanism, as shown in Figure 9(b). However, there was a growth in cracks propagation through the machined surface. This phenomenon might be due to the fact that a negative angle provides greater compressive stresses, as well as a deeper affected zone below the surface, leading to more subsurface damage and surface cracks generation (Dahlman et al., 2004).

Figure 9(c) and Figure 9(d) shows SEM images of surfaces machined under $-30^{\circ}$ and $-45^{\circ}$ rake angles. In addition to more significant surface cracks, the most part of the machined surface had been covered by small chips and particles. There might be two reasons for this phenomenon. Firstly, particles produced during cutting process due to the ploughing effect of the tool are pushed towards the workpiece surface under a highly negative rake angle and accumulated on the surface. Secondly, microcracks propagation near the surface layer of the workpiece material also cause particle generation, which are easily attached to the surface. 
Figure 9 SEM images of surfaces machined at tool rake angles of, (a) $0^{\circ}$ (b) $-15^{\circ}$ (c) $-30^{\circ}$ (d) $-45^{\circ}$ (5000 $\mathrm{X}$ magnification)

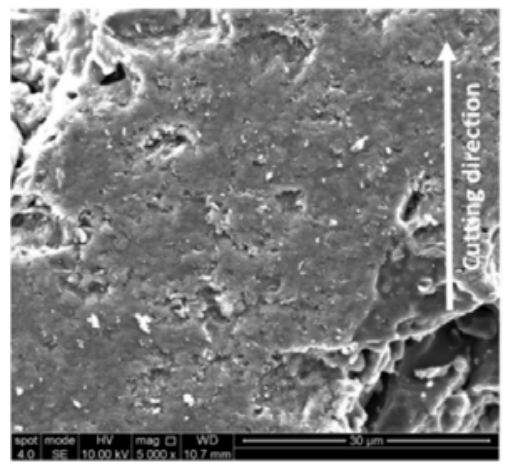

(a)

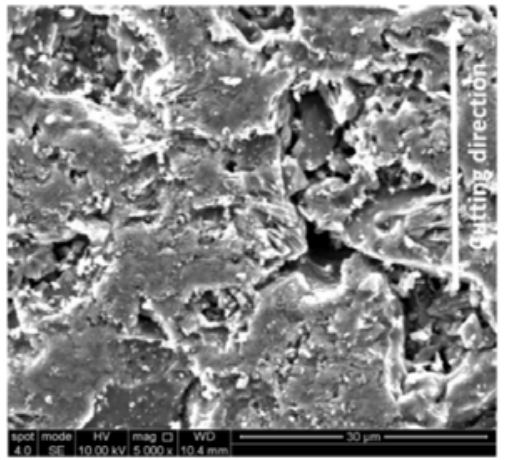

(c)

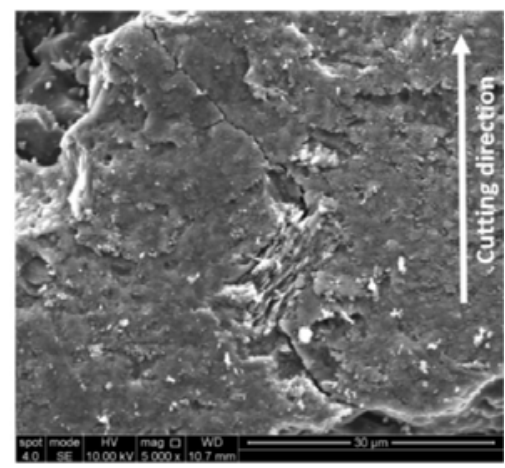

(b)

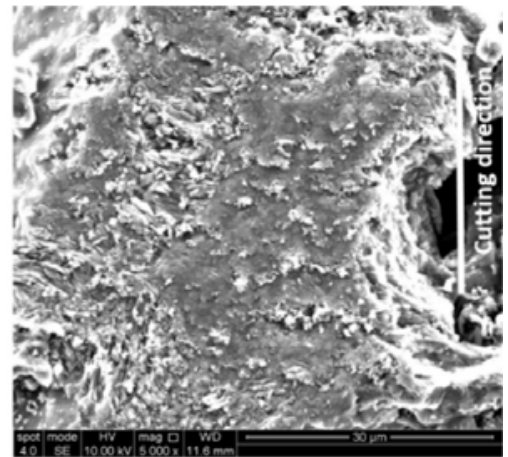

(d)

Figure 10 Schematic illustration of cutting mechanisms under a negative tool rake angle (see online version for colours)

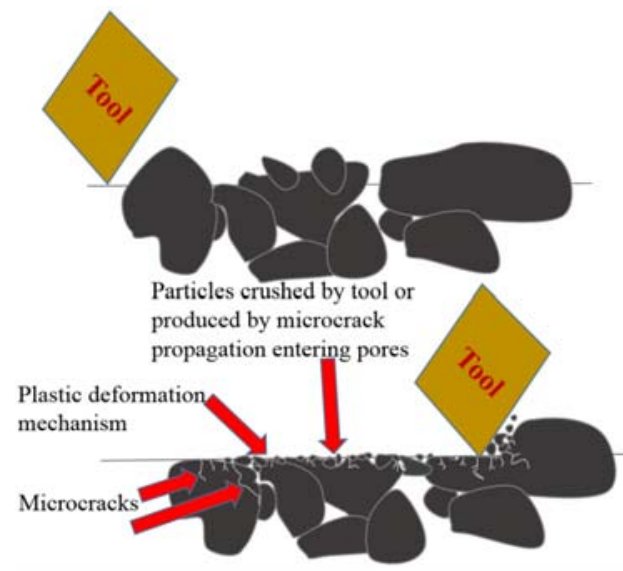


The schematic illustration of particle generation during machining process under a negative rake angle is shown in Figure 10. As particle generation affects the surface integrity and surface cleanness, it is important to avoid using a highly negative rake angle when cutting porous carbon.

\subsection{Surface roughness analysis}

Surface roughness was measured in both two-dimensional (2D) and three-dimensional (3D) forms. Figure 11(a) is a typical 2D surface profile of the machined surface, from which the algorithmic average surface roughness $R_{a}$ was calculated. Figure $11(\mathrm{~b})$ is a typical 3D profile of the machined surface roughness of porous carbon, from which the average arithmetical deviation of area $(\mathrm{Sa})$ was calculated by using the TalyMap software as (Davinci et al., 2014; Gadelmawla et al., 2002):

$$
S_{a}=\frac{1}{N M} \sum_{x=0}^{N} \sum_{y=0}^{M-1} Z_{x y}
$$

In this research, $S_{a}$ was used instead of $R_{a}$ to achieve total evaluation of surface characteristics. The experimental data were used to develop a relationship between the three machining parameters and $\mathrm{S}_{\mathrm{a}}$ using regression methodology and ANOVA (Montgomery and Runger, 2012). As shown in Figure 12, the ANOVA of data demonstrated that feed rate had dominant effect on surface roughness $\left(\mathrm{S}_{\mathrm{a}}\right)$ with $55.18 \%$. The depth of cut took the second place with $38.27 \%$. Nevertheless, the cutting speed had negligible effect on $\mathrm{S}_{\mathrm{a}}$ with just $6.54 \%$.

Figure 11 (a) 2D (b) 3D surface topographies for calculating roughness parameters $\mathrm{R}_{\mathrm{a}}$ and $\mathrm{S}_{\mathrm{a}}$ (see online version for colours)

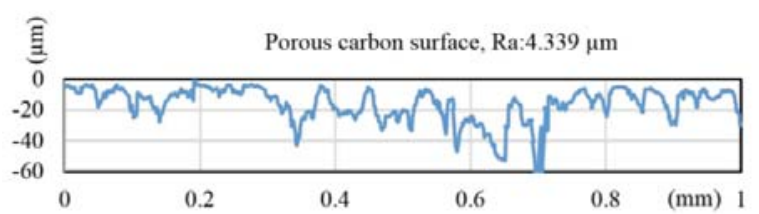

(a)

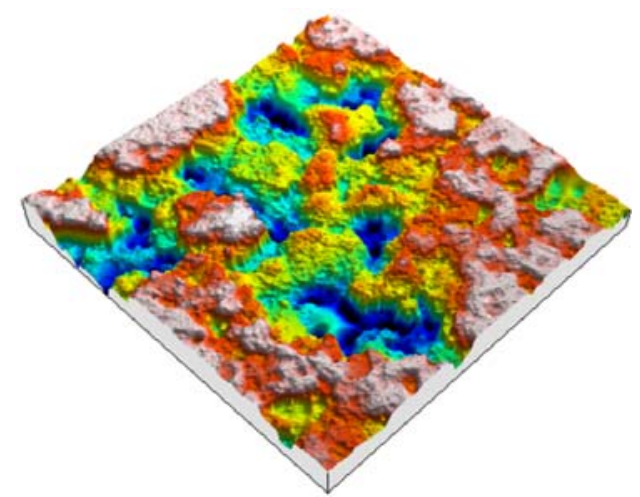

(b) 
Figure 12 The influence of three independent parameters on surface roughness $S_{a}$ (see online version for colours)

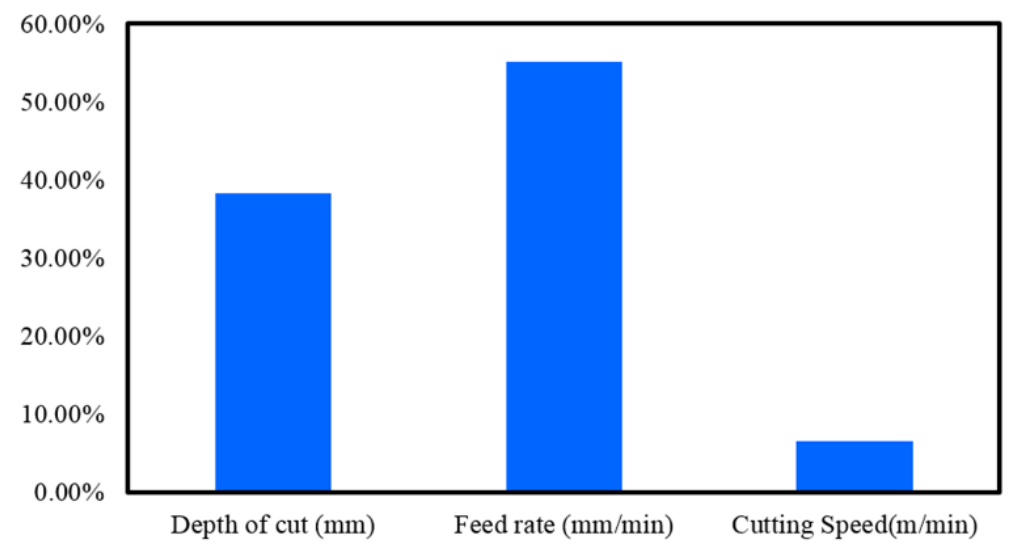

The pairwise effect of feed rate and depth of cut on surface roughness is shown in Figure 13. The points shown by four arrows are the tests performed in high cutting speed $120 \mathrm{~m} / \mathrm{min}$. By and large, increasing the feed rate causes increase in surface roughness, while there is no meaningful relationship between depth of cut and surface roughness in Figure 13.

Figure 13 Effects of feed rate and depth of cut on surface roughness $S_{a}$ (see online version for colours)

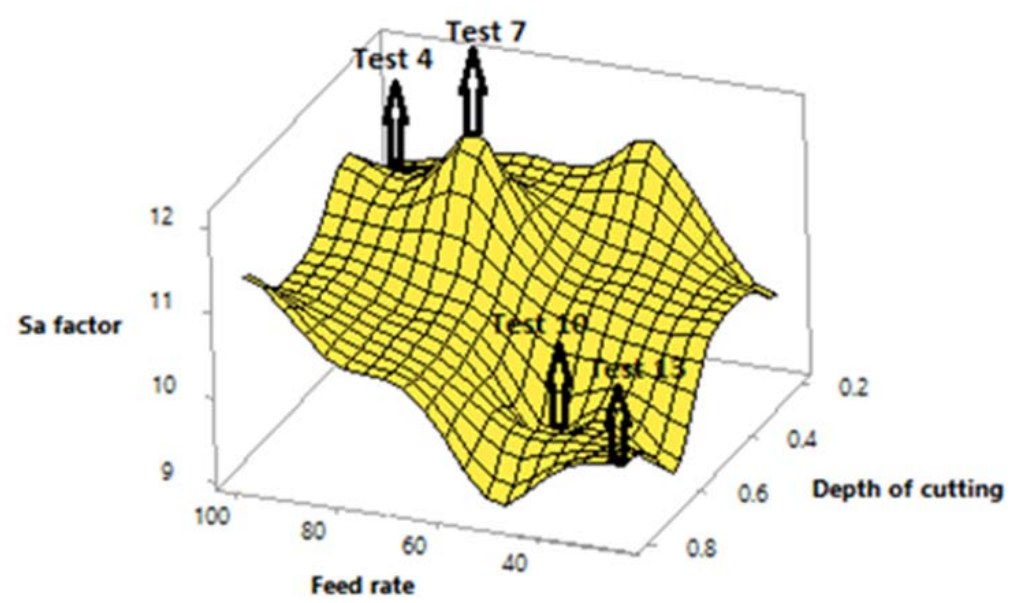

In order to study the impacts of depth of cut, eight cutting tests were carried out at the same cutting speed $(60 \mathrm{~m} / \mathrm{min})$ and feed rate $(50 \mathrm{~mm} / \mathrm{min})$ but different depth of cut from $0.1 \mathrm{~mm}$ to $0.8 \mathrm{~mm}$. As presented in Figure 14(a), by increasing depth of cut, surface roughness factor fluctuated between $6.5 \mu \mathrm{m}$ and $10 \mu \mathrm{m}$, and the trend line (dashed line), which is obtained using linear regression analysis method, demonstrates a slight increase. When depth of cutting increases mechanism of removal will change towards more brittle fracture leaving more curved fracture edges in the craters. This slight increase can be 
seen in Figure 8 in which roughness of surface increases in Figure 8(c) and Figure 8(d) (0.8 mm depth of cut) compared to Figure 8 (a) and Figure $8(\mathrm{~b})(0.2 \mathrm{~mm}$ depth of cut) respectively. However, the effect of feed rate was more obvious in comparison with depth of cut as already explained in Section 4.2.

Figure 14 Effect of, (a) depth of cut (b) tool rake angle on the surface roughness $\mathrm{S}_{\mathrm{a}}$ (see online version for colours)

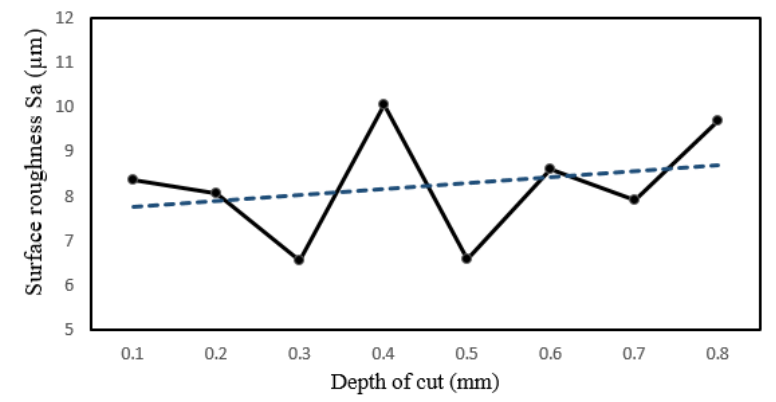

(a)

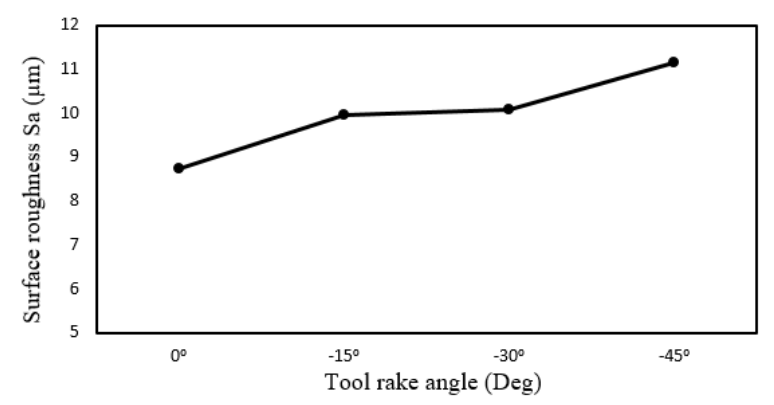

(b)

In addition, Figure 14(b) shows effects of tool rake angle on surface roughness. There is a meaningful increase in roughness by decreasing tool rake angle. This result demonstrated again that a negative tool rake angle is disadvantageous for cutting porous carbon.

\subsection{Bearing area curve}

Considering the application of porous carbon in air bearing, the bearing area curve (Abbot Firestone Curve) is an important indicator of surface quality. According to Anon (2015), the material ratio is defined as the ratio of the intersecting area of a plane (i.e., parallel to the mean plane) passing through the surface at a given height to the cross sectional area of the evaluation region. Bearing area curve is established by evaluating material ratio at various levels from the highest peak to the lowest valley. There are two important parameters to characterise the bearing area curve: core roughness depth Sk and peak height above the core roughness, Spk (alternatively, valley depth below the core roughness Svk), as shown in Figure 15(a) and Figure 15(b). 
Figure 15 (a) and (b) show definition of parameters Spk, Sk and Svk in a bearing area curve (c) and (d) are bearing ratio curves of test 1 and test 4 , respectively (see online version for colours)

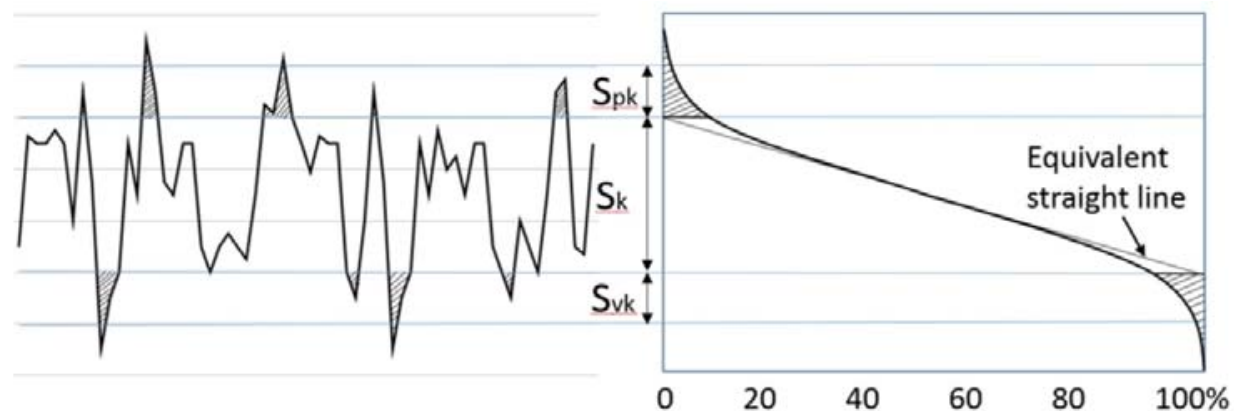

(a)

(b)

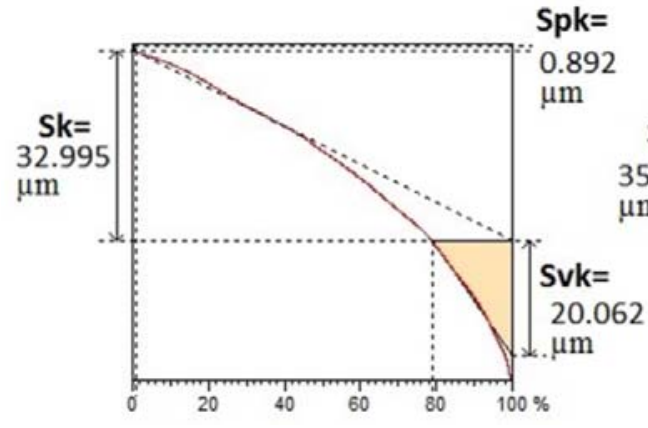

(c)
Spk=

1.072 $\mu \mathrm{m}$

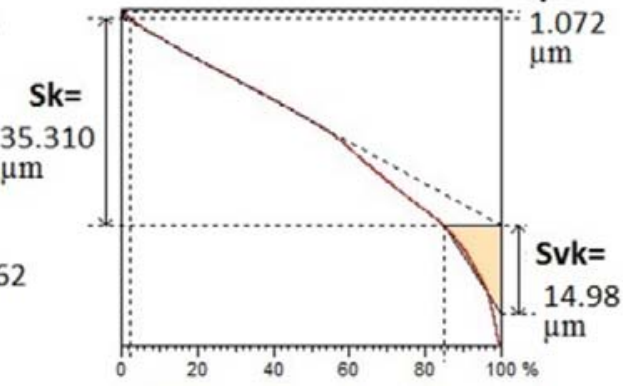

(d)

Analysis of $\mathrm{Sk}$ showed that it followed the same trend as that of $\mathrm{S}_{\mathrm{a}}$ as shown in Figure 13. That is to say, feed rate and depth of cut are the dominate parameters on Sk while cutting speed did not have impact on Sk. In order to consider effect of feed rate on Sk factor, we compared the bearing ratio curves of two experiments at feed rates of 25 and $100 \mathrm{~mm} / \mathrm{min}$ respectively, corresponding to test 1 and 4, 5 and 8,9 and 12 in Table 2 . In each cutting test, 8 areas of the sample were evaluated by the white light interferometer and the Talymap software. For example, Figure 15(c) and Figure 15(d) show the results of tests 1 and 4 .

It is clear that the test at higher feed rate [Figure 15(d)] presented a larger Sk than that at a lower feed rate [Figure 15(c)]. Therefore, increasing feed rate will cause both surface roughness $\left(\mathrm{S}_{\mathrm{a}}\right)$ and core roughness $(\mathrm{Sk})$ to rise. Although increasing $\mathrm{S}_{\mathrm{a}}$ is not desired, increasing $\mathrm{Sk}$ is advantageous because it will improve the capability of carrying the load after initial running-in period for air bearings (Mello, 2005). The effect of depth of cut on Sk indicated the same trend.

Another important factor that should be taken to account is Spk which have strong effects on the ability of a surface to resist wear. In the air bearing application, a small Spk leads to increasing wear resist and the life of part. In this study, the results showed that the Spk in all tests is almost less than $1 \mu \mathrm{m}$, far smaller than Sk, as shown in Figure 15(c) and Figure 15(d). This shows that despite of different cutting conditions, Spk is 
negligibly small. This fact demonstrated again that it is advantageous for using a diamond turned porous carbon surface in air bearing applications (Mello, 2005).

The wear resistance of a surface can also be characterised by skewness distribution graph. Figure 16(a) shows two typical surface profiles and the corresponding skewness distribution. It is known that for a porous carbon surface as porous media air bearings, a negative skew is beneficial (Gadelmawla et al., 2002). In the present study, all diamond turned porous carbon surfaces showed negative skew curves. Figure 16(b) illustrates an example of skewness distribution graph in test 16 of Table 2.

Figure 16 (a) Definition of skewness distribution curve (b) Skewness distribution graph for porous carbon diamond turned at conditions: $f(100 \mathrm{~mm} / \mathrm{min}), v(30 \mathrm{~m} / \mathrm{min})$ and $a(0.8 \mathrm{~mm})$ (see online version for colours)

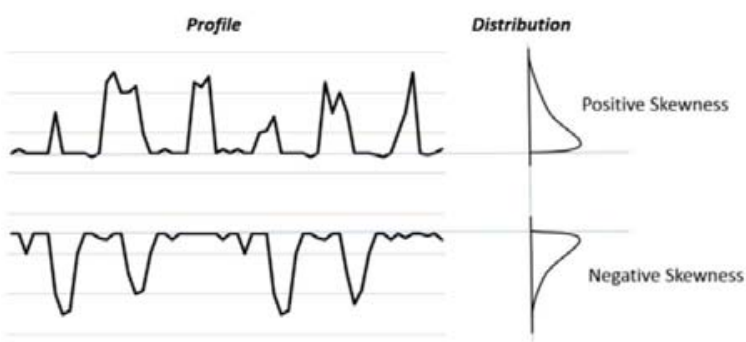

(a)

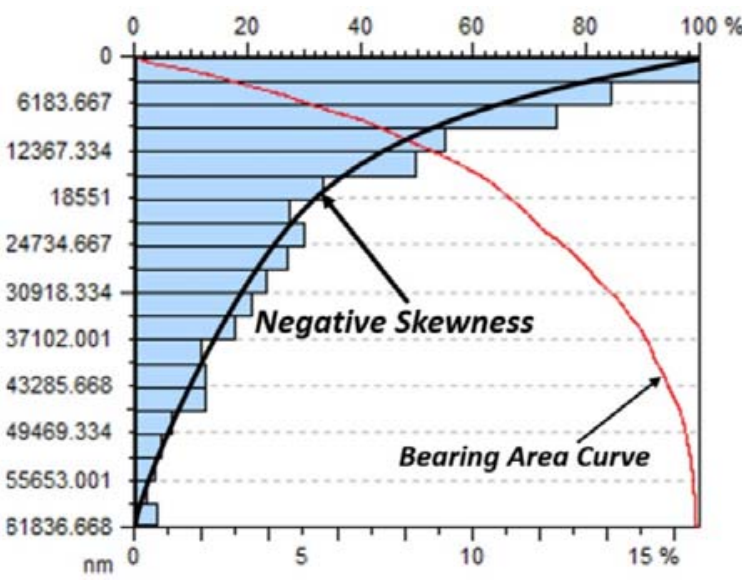

(b)

\subsection{Surface porosity}

The surface porosity of porous carbon plays an essential role in its application as air bearing. To evaluate surface porosity, the ImageJ software was used to analyse SEM images of the machined surfaces. An example of SEM image is shown in Figure 17(a). Then these images were processed to calculate the area ratio of surface pores. Figure 17(b) shows the processed results by the ImageJ software. 
Figure 17 (a) SEM image of a diamond turned surface (b) Image-processed results for calculating surface porosity

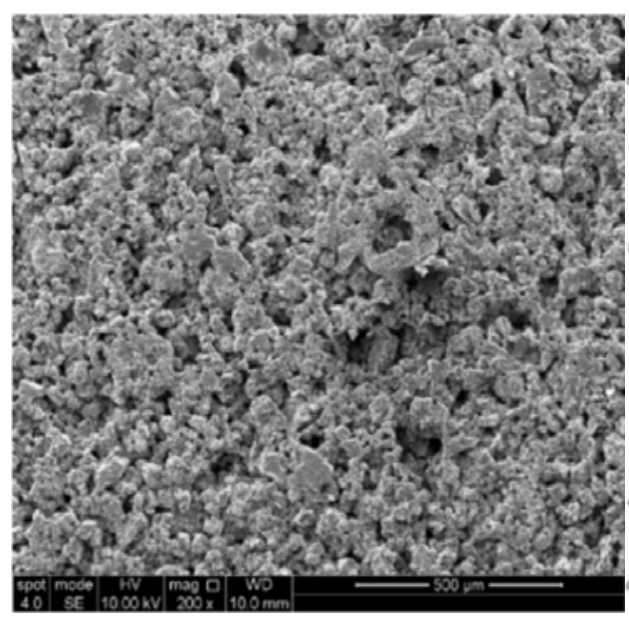

(a)

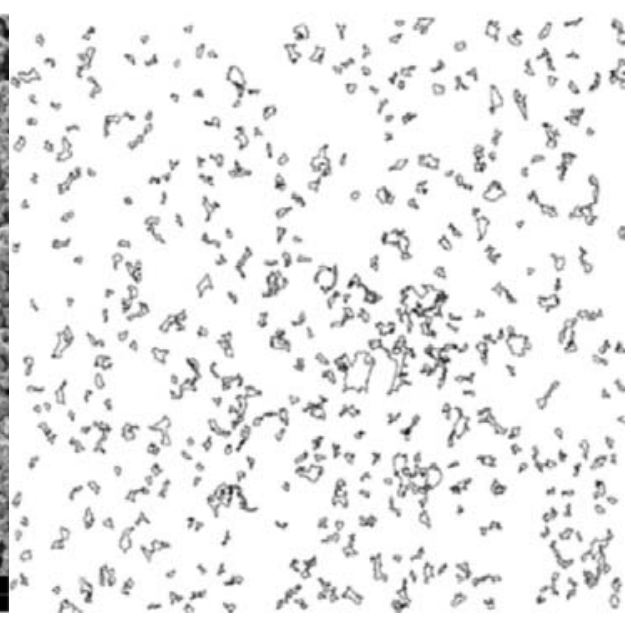

(b)

Figure 18 Effects of, (a) three machining parameters (b) tool rake angle on surface porosity (see online version for colours)

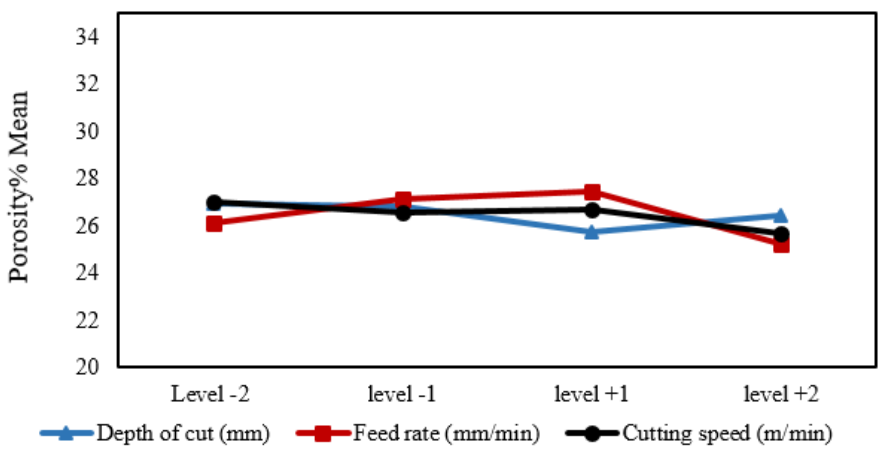

(a)

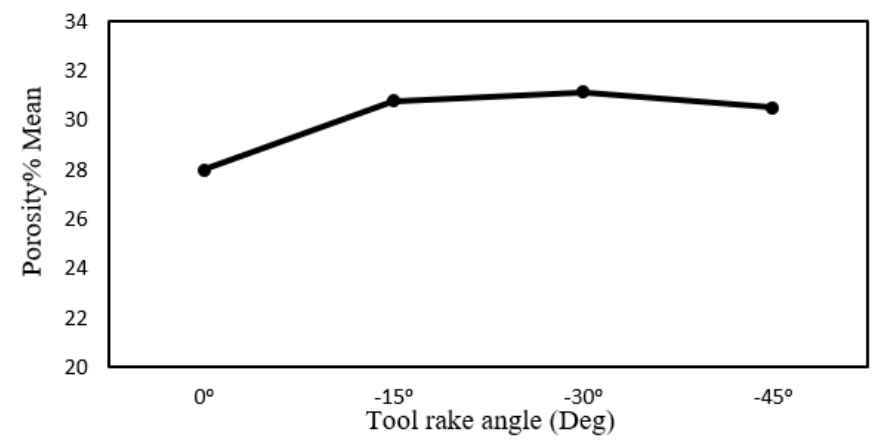

(b) 
Figure 18(a) illustrates the effects of depth of cut, feed rate and cutting speed on surface porosity. Figure 18(b) presents effect of tool rake angle on porosity. In both cases, there is no strong dependence of porosity on the machining parameters and tool rake angle. All machined samples showed an average of about $25 \%$ decrease in porosity after machining, which is acceptable for air bearing applications (Panzera et al., 2005). It is worth nothing that pressed particles into pores and rotating grains towards pores, which causes pores to be closed during cutting process, are the main reasons in decreasing porosity percentage.

\section{Conclusions}

The fundamental material removal phenomena in diamond turning of porous carbon were investigated experimentally. The following conclusions were drawn.

1 Three major mechanisms were involved in material removal, namely, plastic deformation, brittle fracture and grain rotation. The brittle fractures can be further divided into two types: grain boundary fractures and grain bulk fractures.

2 Among the three independent cutting parameters, feed rate was the most important factor with $55.18 \%$. affecting the surface formation and surface roughness, and the second one was depth of cut with $38.27 \%$; whereas cutting speed has no significant impact with just $6.54 \%$.

3 Tool rake angle influenced both material removal behaviour and surface roughness (It has increased surface roughness from 8.73 to $11.14 \mu \mathrm{m}$ ). A negative tool rake angle was disadvantageous for machining porous carbon.

4 The diamond-turned porous carbon surface has an extremely small peak height, a high core roughness, and a negative skewness distribution, which are advantageous for air bearing applications.

5 The diamond-turned porous carbon surface has an average porosity of $26.5 \%$, about $25 \%$ decrease in porosity compared with that before machining.

The results from the present study preliminarily demonstrated the possibility of fabricating high-precision air bearings of porous carbon directly by diamond turning.

\section{Acknowledgements}

The authors would like to acknowledge Mr. Kitahara Makoto and TANKEN SEAL SEIKO CO., LTD. to support and provide porous carbon samples for this research. 


\section{References}

Anon (2015) Michigan Metrology 3D Surface Roughness Measurement and Wear Measurement, Analysis and Inspection.

Chen, S., Head, D. and Jawahir, I.S. (2004) 'An investigation of machining performance for controlled surface quality requirements in porous tungsten [for dispenser cathodes]', Fifth IEEE International Vacuum Electronics Conference, IEEE Cat. No. 04EX786, pp.358-359, IEEE.

Dahlman, P., Gunnberg, F. and Jacobson, M. (2004) 'The influence of rake angle, cutting feed and cutting depth on residual stresses in hard turning', Journal of Materials Processing Technology, Vol. 147, No. 2, pp.181-184.

Davinci, M.A. et al. (2014) 'Effect of the tracing speed and span on roughness parameters determined by stylus type equipment', Measurement, Vol. 48, pp.368-377.

Fan, C. et al. (2015) 'Novel approach to the characterization of the pore structure and surface chemistry of porous carbon with $\mathrm{Ar}, \mathrm{N}_{2}, \mathrm{H}_{2} \mathrm{O}$ and $\mathrm{CH}_{3} \mathrm{OH}$ adsorption', Microporous and Mesoporous Materials, Vol. 209, pp.79-89.

Gadelmawla, E.S. et al. (2002) 'Roughness parameters', Journal of Materials Processing Technology, Vol. 123, No. 1, pp.133-145.

Kalpakjian, S. and Schmid, S. (2009) Manufacturing Engineering and Technology, 6th ed., Pearson Education India, New York.

Mello, J.D.B. (2005) 'Influence of surface topography on the surface durability of steam oxidised sintered iron', Materials Research, Vol. 8, No. 2, pp.135-141.

Mohammadi, H. et al. (2015) 'Surface finish improvement of an unpolished silicon wafer using micro-laser assisted machining', International Journal of Abrasive Technology, Vol. 7, No. 2, pp.107-121.

Montgomery, D.C. and Runger, G. (2012) Introduction To Linear Regression Analysis, 3rd. ed., John Wiley \& Sons.

Nee, A.Y.C., Song, B. and Ong, S-K. (Eds.) (2013) Re-Engineering Manufacturing for Sustainability, Springer, Singapore.

Panzera, T.H., Carlos, J. and Rubio, C. (2005) 'A survey on ceramic composites for application in porous bearing', 18th International Congress of Mechanical Engineering, Ouro Preto, MG.

Pusavec, F. (2012) 'Porous tungsten machining under cryogenic conditions', International Journal of Refractory Metals and Hard Materials, Vol. 35, pp.84-89.

Reddy, M.R. (2011) 'Effect of feed rate on the generation of surface roughness in turning', International Journal of Engineering Science and Technology (IJEST), Vol. 3, No. 11, pp.8099-8105.

Totten, G.E., Xie, L. and Funatani, K. (2003) Handbook of Mechanical Alloy Design, edited by G.E. Totten, L. Xie, and K. Funatani, CRC Press, New York.

Wei, M. and Wang, J. (2015) 'A novel acetylcholinesterase biosensor based on ionic liquids-AuNPs-porous carbon composite matrix for detection of organophosphate pesticides', Sensors and Actuators B: Chemical, Vol. 211, pp.290-296.

Yan, J. et al. (2002) 'Ductile regime turning at large tool feed', Journal of Materials Processing Technology, Vol. 121, Nos. 2-3, pp.363-372. 